\title{
Multipoint Conjugate Observations of Dayside ULF Waves during an Extended Period of Radial IMF
}

Shi, Xiaodong; Hartinger, M. D.; Baker, J. B. H.; Ruohoniemi, J. M.; Lin, D.; Xu, Z.; Coyle, S.; Kunduri, B. S. R.; Kilcommons, L. M.; Willer, A.

Published in:

Journal of Geophysical Research: Space Physics

Link to article, DOI:

10.1029/2020JA028364

Publication date:

2020

Document Version

Publisher's PDF, also known as Version of record

Link back to DTU Orbit

Citation (APA):

Shi, X., Hartinger, M. D., Baker, J. B. H., Ruohoniemi, J. M., Lin, D., Xu, Z., Coyle, S., Kunduri, B. S. R., Kilcommons, L. M., \& Willer, A. (2020). Multipoint Conjugate Observations of Dayside ULF Waves during an Extended Period of Radial IMF. Journal of Geophysical Research: Space Physics, 125(11).

https://doi.org/10.1029/2020JA028364

\section{General rights}

Copyright and moral rights for the publications made accessible in the public portal are retained by the authors and/or other copyright owners and it is a condition of accessing publications that users recognise and abide by the legal requirements associated with these rights.

- Users may download and print one copy of any publication from the public portal for the purpose of private study or research.

- You may not further distribute the material or use it for any profit-making activity or commercial gain

- You may freely distribute the URL identifying the publication in the public portal 


\section{JGR Space Physics}

\section{RESEARCH ARTICLE \\ 10.1029/2020JA028364 \\ Multipoint Conjugate Observations of Dayside ULF Waves During an Extended Period of Radial IMF}

\section{Special Section: \\ Probing the Magnetosphere through Magnetoseismology and Ultra-Low-Frequency Waves}

Key Points:

- Pc5 ULF waves were observed across the whole dayside from $L \sim 5.5$ into the polar cap region, in contrast to typical conditions

- Coordinated space and ground observations indicate that the waves on closed field lines were due to fundamental standing Alfvén waves

- The ion foreshock during radial IMF conditions provides seed perturbations for the growth of $\mathrm{KH}$ waves which generate the dayside ULF waves

Correspondence to:

X. Shi,

xueling7@vt.edu

Citation:

Shi, X., Hartinger, M. D., Baker, J. B. H., Ruohoniemi, J. M., Lin, D., Xu, Z., et al. (2020). Multipoint conjugate observations of dayside ULF waves during an extended period of radial IMF. Journal of Geophysical Research: Space Physics, 125, e2020JA028364. https://doi.org/10.1029/2020JA028364

Received 19 JUN 2020

Accepted 22 OCT 2020

Accepted article online 9 NOV 2020

(C)2020. American Geophysical Union. All Rights Reserved.

\author{
X. Shi ${ }^{1,2}$ (D) M. D. Hartinger ${ }^{1,3}$ D, J. B. H. Baker ${ }^{1}$ D, J. M. Ruohoniemi' ${ }^{1}$, D. Lin' ${ }^{2}$, Z. Xu' ${ }^{1}$,

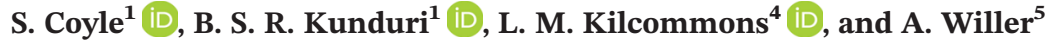 \\ ${ }^{1}$ Department of Electrical and Computer Engineering, Virginia Polytechnic Institute and State University, Blacksburg, \\ VA, USA, ${ }^{2}$ High Altitude Observatory, National Center for Atmospheric Research, Boulder, CO, USA, ${ }^{3}$ Space Science \\ Institute, Boulder, CO, USA, ${ }^{4}$ Aerospace Engineering Sciences, University of Colorado Boulder, Boulder, CO, USA, \\ ${ }^{5}$ National Space Institute, Technical University of Denmark, Kongens Lyngby, Denmark
}

\begin{abstract}
Long-lasting Pc5 ultralow frequency (ULF) waves spanning the dayside and extending from $L \sim 5.5$ into the polar cap region were observed by conjugate ground magnetometers. Observations from MMS satellites in the magnetosphere and magnetometers on the ground confirmed that the ULF waves on closed field lines were due to fundamental toroidal standing Alfvén waves. Monochromatic waves at lower latitudes tended to maximize their power away from noon in both the morning and afternoon sectors, while more broadband waves at higher latitudes tended to have a wave power maximum near noon. The wave power distribution and MMS satellite observations during the magnetopause crossing indicate surface waves on a Kelvin-Helmholtz $(\mathrm{KH})$ unstable magnetopause coupled with standing Alfvén waves. The more turbulent ion foreshock during an extended period of radial interplanetary magnetic field (IMF) likely plays an important role in providing seed perturbations for the growth of the $\mathrm{KH}$ waves. These results indicate that the Pc5 waves observed on closed field lines and on the open field lines of the polar cap were from the same source.
\end{abstract}

Plain Language Summary The Earth's magnetic field lines can oscillate at ultralow frequencies (ULF: $1 \mathrm{mHz}$ to $5 \mathrm{~Hz}$ ). These natural oscillations of closed magnetic field lines, analogous to vibrations on a stretched string, are also called geomagnetic pulsations or ULF waves. ULF waves play a key role in the transfer of energy from terrestrial space to Earth's upper atmosphere. In this study, we report a long-lasting large spatial scale ULF wave event observed by ground observatories from both hemispheres. Together with satellite measurements in space, we are able to confirm that these waves were driven by upstream turbulent structures due to the interaction between matter and electromagnetic fields emitted from the Sun and the Earth's outer atmosphere and magnetic field.

\section{Introduction}

Ultralow frequency (ULF; $1 \mathrm{mHz}$ to $5 \mathrm{~Hz}$ ) waves were identified as micropulsations or geomagnetic pulsations on the ground over 50 years ago (e.g., Jacobs et al., 1964). Since then, they have been recognized to play an important role in magnetospheric plasma energization/loss and energy transfer from the solar wind to Earth's magnetosphere and ionosphere (Elkington et al., 1999; Mathie \& Mann, 2000; Rae et al., 2005). For example, they modulate ionospheric parameters (Pilipenko et al., 2018), affect GPS (Karatay et al., 2010; Pilipenko et al., 2014), and cause ionospheric heating (Crowley et al., 1985; Dessler, 1959). On the one hand, ULF waves driven by external sources from the solar wind can accelerate particles in the ring current and radiation belts through drift-bounce resonance (Zong et al., 2017). On the other hand, they can be driven by unstable particle distributions in the magnetosphere (e.g., Baddeley et al., 2005; Shi et al., 2014) and dissipate their energy to the ionosphere via Joule heating through field line resonances (FLRs) (Hartinger et al., 2011; Rae et al., 2005). When propagating to the ground, ULF waves provide a useful diagnostic probe of several magnetospheric properties (Menk et al., 1999) and can potentially drive geomagnetically induced currents (GIC) that may damage technological infrastructures (Pulkkinen \& Kataoka, 2017; Pulkkinen et al., 1999). The spatial variation of the frequency and amplitude of geomagnetic perturbations is particularly important for predicting GIC and radiation belt dynamics and for remote sensing magnetospheric parameters. 
The excitation of toroidal Pc5 waves is mainly due to external sources, that is, an energy source in the solar wind, magnetosheath, or magnetopause/boundary layer. Coherent oscillations in solar wind parameters can penetrate and directly drive ULF waves inside the magnetosphere (Kepko \& Spence, 2003). ULF waves can also be generated by buffeting of the magnetosphere in response to solar wind pressure perturbations, such as positive or negative dynamic pressure pulses (Zhang et al., 2013). Surface waves that are unstable to the Kelvin-Helmholtz (KH) instability on the flanks of the magnetosphere are another external source for ULF wave generation (Miura, 1992). Surface waves can set up global waveguide modes, and both surface waves and waveguide modes can couple to standing shear Alfvén waves through mode conversion (Rae et al., 2006). These shear Alfvén waves are often referred to as FLRs. In this study, we will not differentiate between resonant and nonresonant mode conversion.

Upstream waves originating from the ion foreshock have long been thought to drive dayside Pc3-4 pulsations (Takahashi et al., 2016; Yumoto et al., 2017), which is favored under predominately radial interplanetary magnetic field (IMF) or low cone angle conditions (Bier et al., 2014; Russell et al., 2016). More recent observations have shown that foreshock disturbances, such as hot flow anomalies, can also drive compressional Pc5 waves and FLRs in the dayside magnetosphere and ionosphere with significant amplitude (Hartinger et al., 2013; Shen et al., 1983; Wang et al., 2009). Hybrid simulations have also shown that high-speed jets and low-frequency waves can form downstream of the quasi-parallel shock in the magnetosheath (Omidi et al., 2014; Palmroth et al., 2015, 2018); these foreshock associated disturbances and ULF waves can act as seed fluctuations for the generation of KH waves on the magnetopause (Miura, 1992).

In this study, we report long-lasting Pc5 waves with an unusually large spatial extent (from $L \sim 5.5$ to the polar cap region on the dayside) observed by conjugate ground magnetometers during an extended period of radial IMF condition on 25 January 2016; on closed field lines, these correspond to the fundamental toroidal mode. We argue that these waves are due to magnetopause surface waves caused by a $\mathrm{KH}$ unstable magnetopause seeded by foreshock transients.

\section{Observations}

\subsection{Event Overview}

Figure 1 provides an overview of the interplanetary and geomagnetic conditions during the event and maps showing locations of ground magnetometers and footprints of other measurements from satellites. The interplanetary parameters (Figures 1a-1c) are obtained from the WIND satellite, time shifted by 45 min. As shown in Figures $1 \mathrm{a}$ and $1 \mathrm{~b}$, the IMF is dominated by the $B_{x}$ component (red curve) which leads to a low cone angle condition and very quiet geomagnetic activity throughout the day (Figure 1d). No obvious periodic or abrupt perturbations were observed in the solar wind velocity or dynamic pressure (Figure 1c). However, large spatial scale long-lasting ULF waves were observed by two conjugate latitudinal ground magnetometer chains (Figure 1e). Black traces indicate measurements from geomagnetic stations along the west coast of Greenland operated by the Technical University of Denmark (DTU). Red traces indicate measurements from the Autonomous Adaptive Low Power Instrument Platform (AAL-PIP) ground magnetometer chain located on the $40^{\circ}$ magnetic meridian between the $80^{\circ}$ and $85^{\circ}$ south geographic latitude, 70-79 ${ }^{\circ}$ magnetic latitude (Clauer et al., 2014). Note that the time resolution from both ground magnetometer chains is $1 \mathrm{~s}$ except for the ATU station which is $10 \mathrm{~s}$. (There were data quality issues with the ATU station on this date, so we only show its time series in Figure 1e and exclude it from further analysis in the following sections.)

The auroral image obtained from the Special Sensor Ultraviolet Spectrographic Imager (SSUSI) on board the Defense Meteorological Satellite Program (DMSP) satellite shows that ULF waves were observed on both closed and open magnetic field lines (Figure 1f). Black (red) stars indicate locations of the DTU (AALPIP) stations. The AAL-PIP stations (PG1-5) were mapped from the Southern Hemisphere using the T96 external model and IGRF08 internal model. PG0 appears to be on T96 open field lines and so cannot be mapped to the Northern Hemisphere. Special Sensor J (SSJ) measurements from DMSP (not shown) also indicate that THL was in the polar cap region and that soft electron precipitation was observed above it (Kilcommons et al., 2017). Figure $1 \mathrm{~g}$ shows footprints of the MMS1 satellite from 15 to 23 UT on 25 January 2016 and the locations of ground magnetometers and two SuperDARN radars in the Northern Hemisphere in Altitude-adjusted corrected geomagnetic coordinates (AACGM) (Shepherd, 2014). The 

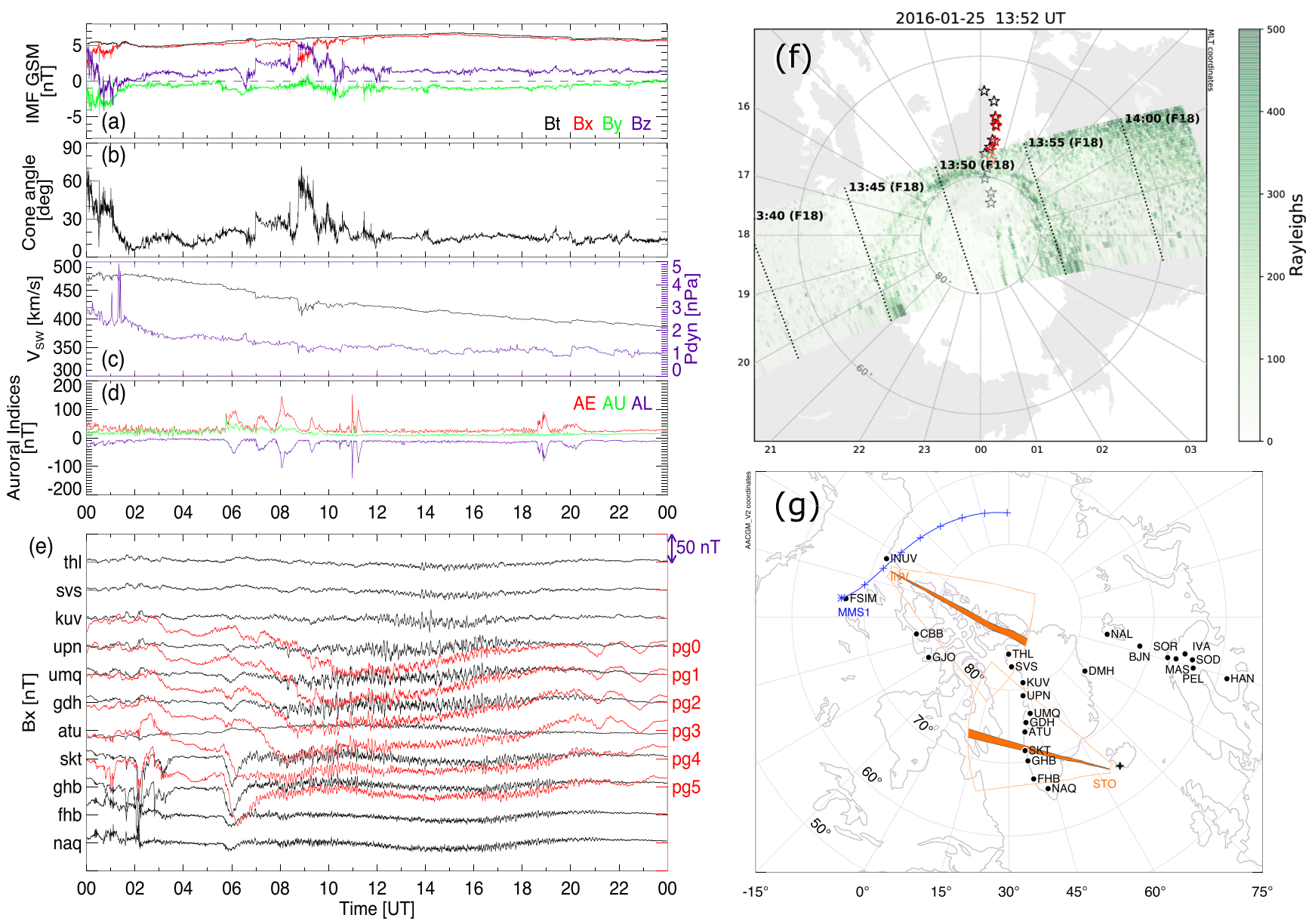

Figure 1. Event overview: (a) IMF components in GSM coordinates; (b) IMF cone angle; (c) solar wind velocity (black) and dynamic pressure (purple); (d) auroral indices; (e) time series of northward magnetic field component $\left(B_{x}\right)$ in conjugate ground magnetometer observations from the DTU (black lines) stations in the Northern Hemisphere and the AAL-PIP (red lines) stations in the Southern Hemisphere; maps showing (f) DMSP SSUSI image (green pixels), locations of the DTU (black star), and AAL-PIP (red star, mapped from the Southern Hemisphere using the T96 external model and IGRF08 internal model) stations in magnetic local time coordinates and (g) footprint of MMS1 (blue curve) from 15 to 23 UT on 25 2016, selected ground magnetometers (black dot), fields of view, and selected beams (orange shaded regions) of two SuperDARN radars in AACGM coordinates.

Flux Gate Magnetometers (FGM) (Russell et al., 2008) and Fast Plasma Investigation (FPI) (Pollock et al., 2018) data from MMS1 satellite will be analyzed in section 2.3. Ground magnetometer data from two latitudinal chains DTU and IMAGE (Tanskanen, 2013) and one longitudinal chain (NAL-DMHUMQ-GJO-CBB) will be analyzed in section 2.2 (Figures 2 and 3). Data from the FSIM and INUV stations will be analyzed in section 2.3 (Figure 6). More information about all the ground magnetometers used in this study, including the $L$ value are shown in Table 1 .

\subsection{Observations From the Ground}

In this section we present wave properties from ground magnetometer observations in both hemispheres. Figure 2 shows dynamic power spectra of magnetic field data from the two latitudinal (upper panels) and longitudinal (lower panels) chains in the Northern Hemisphere. The spectra were obtained by applying a 60 min running fast Fourier transform (FFT) and incrementing by 15 min so that the evolution of the wave power can be obtained. Prior to taking the FFT, the data were detrended by subtracting a 30 min running average, and a Hanning window was applied to reduce spectral leakage.

The panels in Figures 2a and $2 b$ show the wave spectral power variation with latitude from the DTU chain. Noon is denoted by the second vertical line. Pc5 pulsations were mainly observed on the dayside with wave 
(a) DTU Bx, Jan 25, 2016

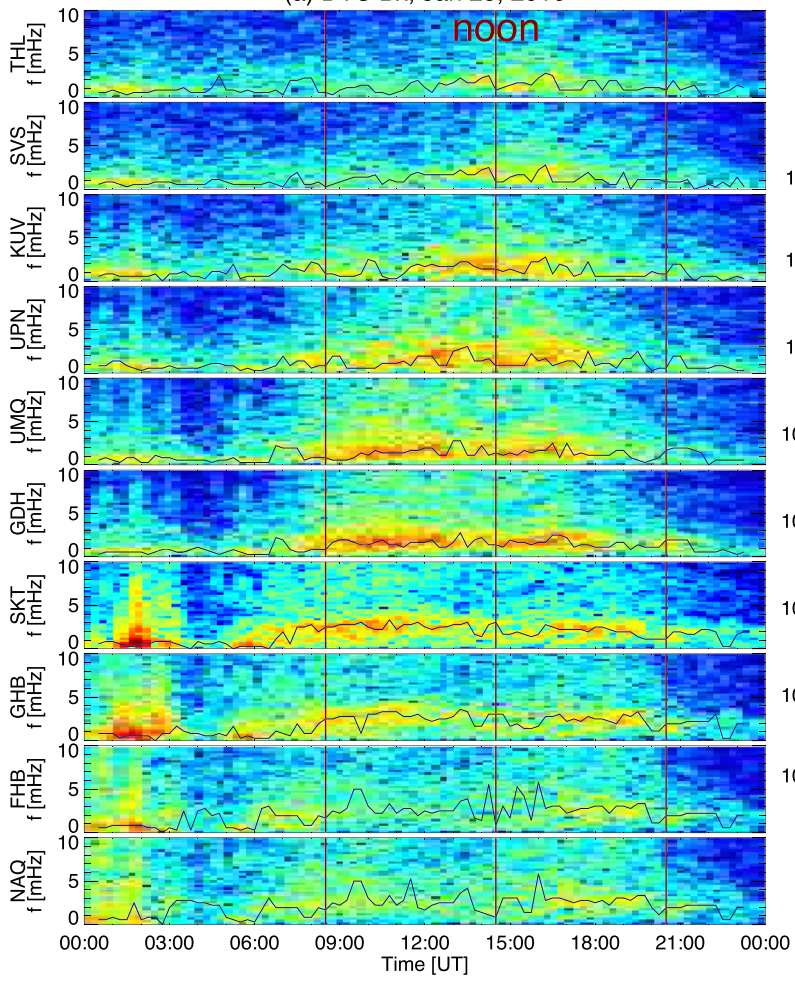

(c) Bx, Jan 25, 2016

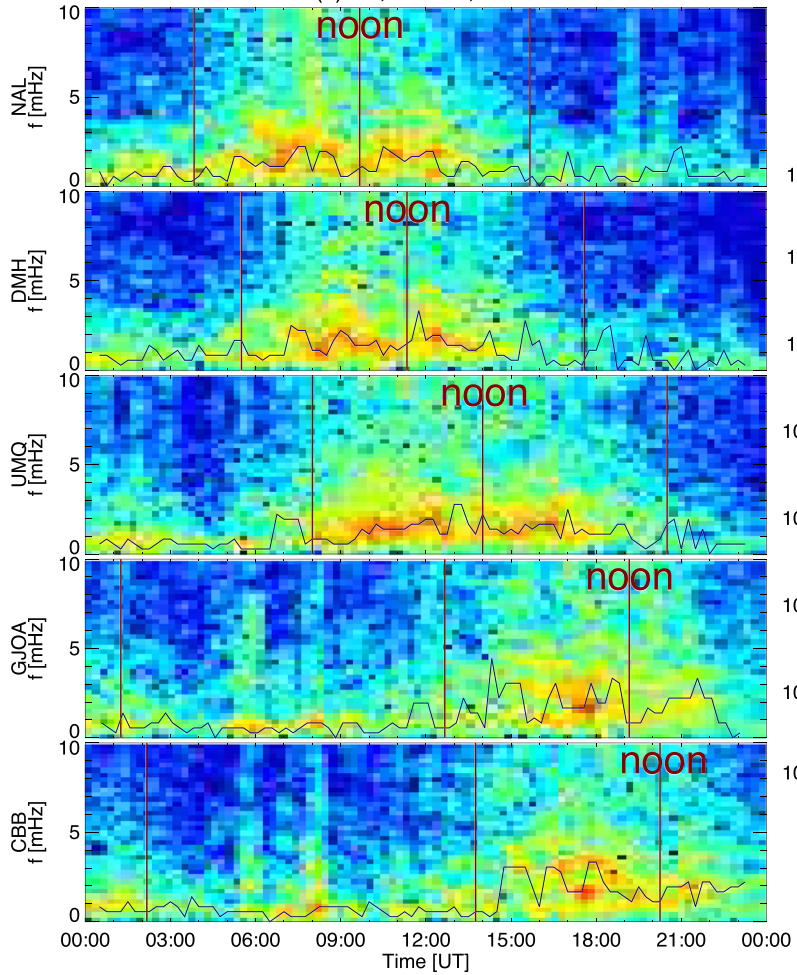

(b) DTU By, Jan 25, 2016

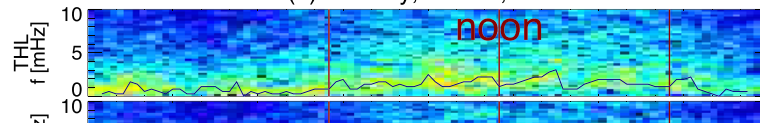

$\stackrel{\infty}{\stackrel{N}{T}}$

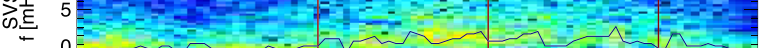

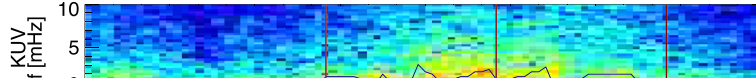

$0=2$ ran

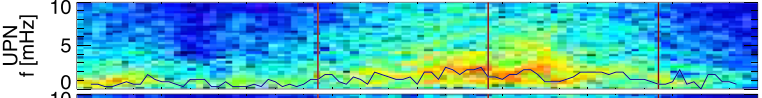

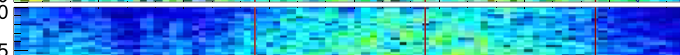

西

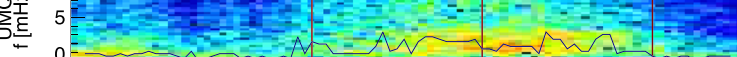

I

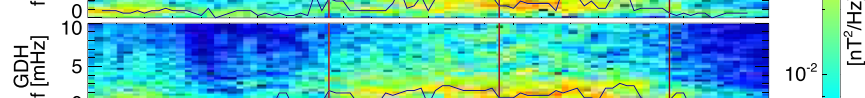

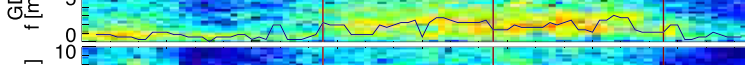

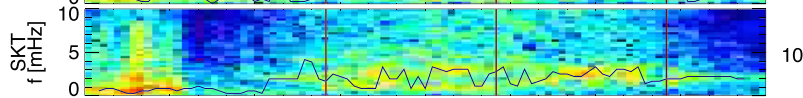

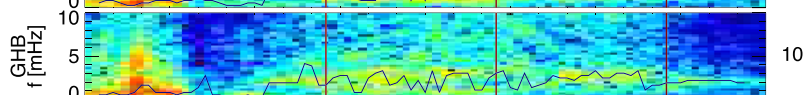

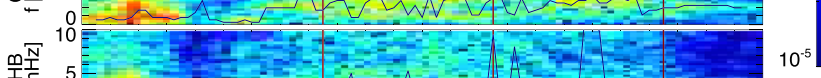

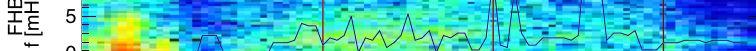

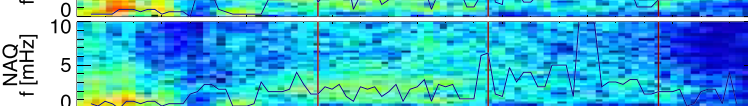

$00: 00 \quad 03: 00 \quad 06: 00 \quad 09: 00 \quad 12: 00 \quad 15: 00 \quad 18: 00 \quad 21: 00 \quad 00: 00$

(d) By, Jan 25, 2016

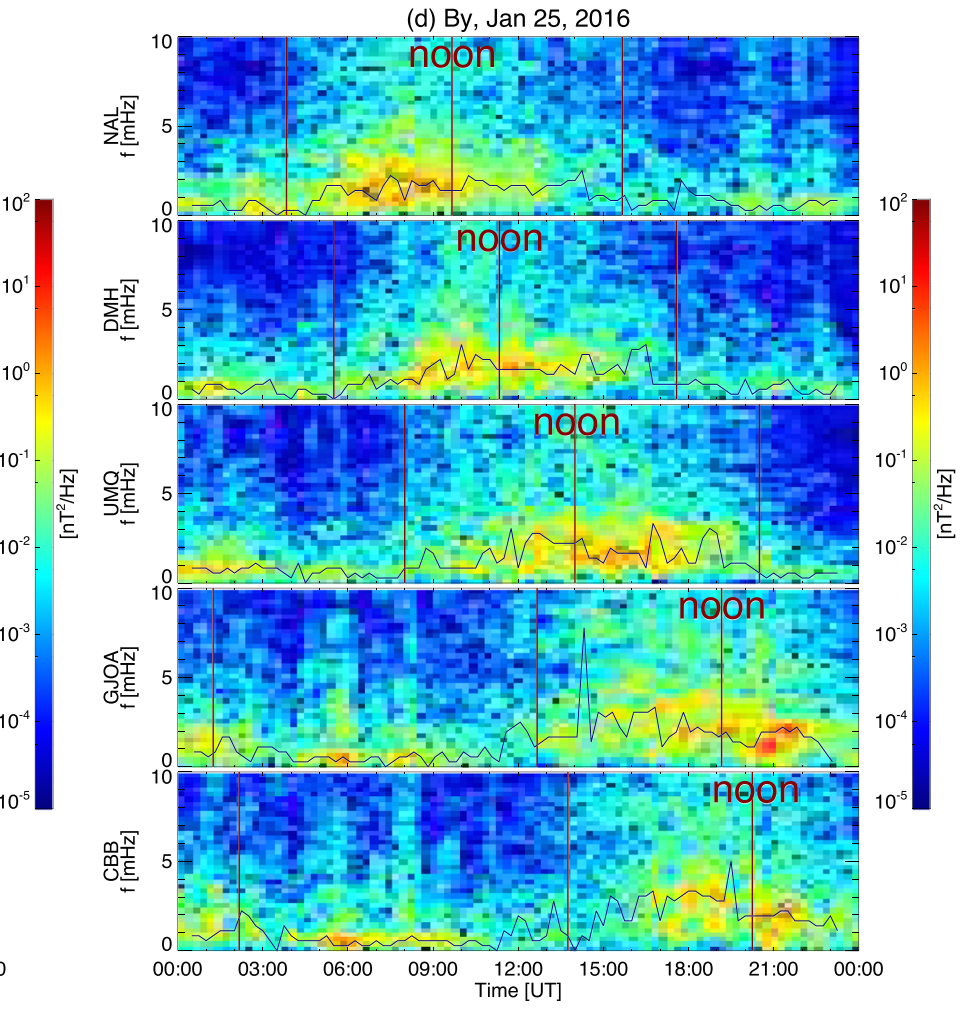

Figure 2. Dynamic power spectra of ground magnetic field (a) northward component $\left(B_{x}\right)$ observed at the DTU stations, (b) eastward component ( $\left.B_{y}\right)$ observed at the DTU stations, (c) northward component $\left(B_{x}\right)$ observed at the longitudinal chain stations, and (d) eastward component $\left(B_{y}\right)$ observed at the longitudinal chain stations. Vertical lines indicate magnetic local times at 6, 12, and $18 \mathrm{~h}$. Black solid traces identify the peak power frequency variation with time. 


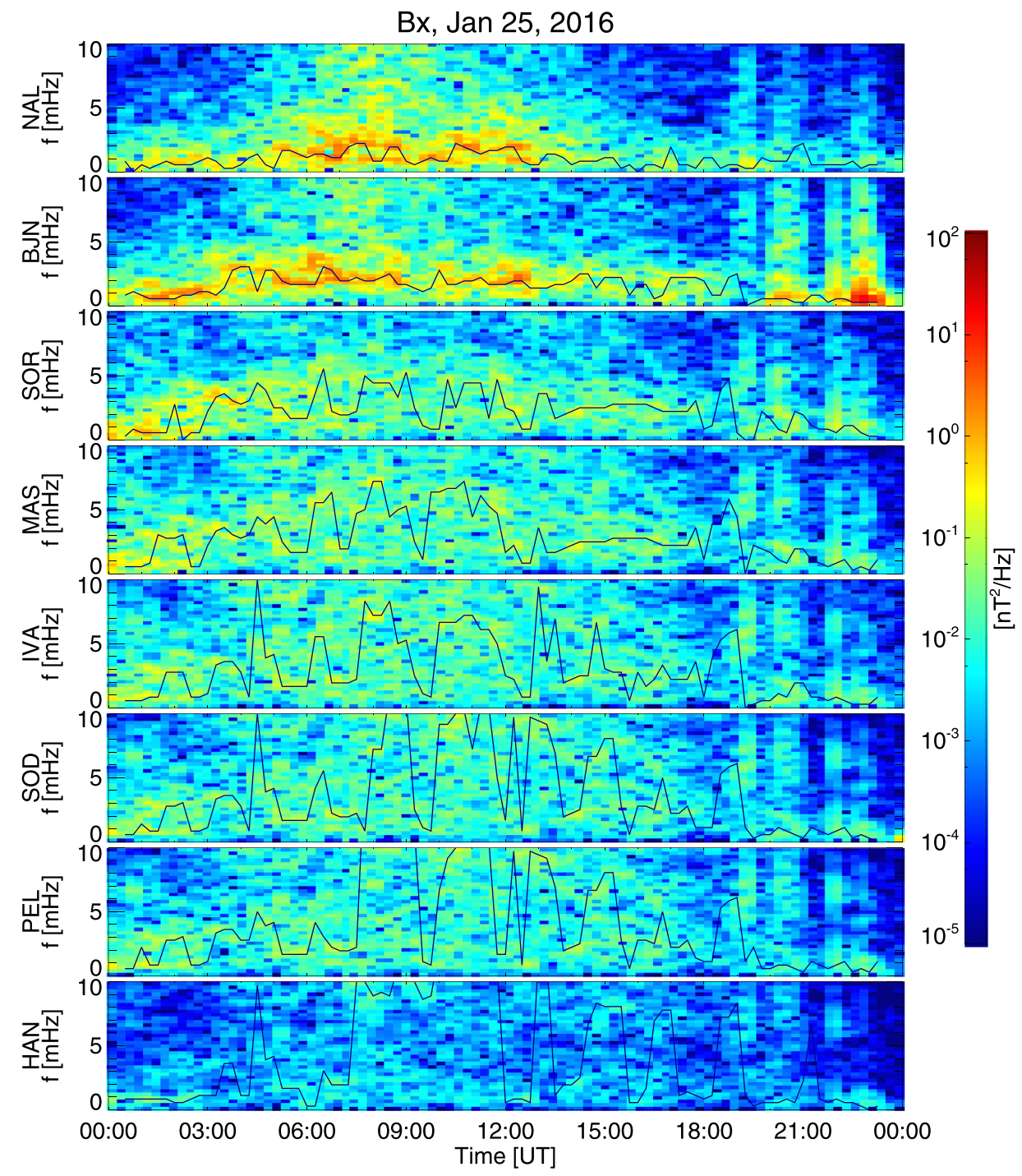

Figure 3. Dynamic power spectra of ground magnetic field northward component $\left(B_{x}\right)$ observed at the IMAGE stations. Black solid traces identify the peak power frequency variation with time.

peak power frequency (black solid curve) slightly increasing with decreasing latitude (from top to bottom). It can be seen that the frequency stays fairly constant at all local times on the dayside. Wave power from lower latitudes (more monochromatic waves) tends to maximize away from noon in the morning/afternoon sector, while wave power from higher latitudes (more irregular waves) tends to maximize near noon. Lower (higher) latitudes here mean latitudes below (above) the GDH station. Comparing Figure 2a $\left(B_{x}\right)$ with Figure $2 \mathrm{~b}\left(B_{y}\right)$ reveals that wave power in the morning sector is generally greater in the $B_{x}$ component (toroidal mode, Figure 2a) than in the $B_{y}$ component (poloidal mode, Figure 2b). However, the wave power is comparable for both components in the afternoon sector.

The panels in Figures $2 \mathrm{c}$ and $2 \mathrm{~d}$ show the wave spectral power variation with local time from the longitudinal chain (see Figure $1 \mathrm{~g}$ for locations). It can be clearly seen that ULF wave activity persisted across the whole dayside throughout the entire day. Five ground magnetometers located at similar magnetic latitudes but different magnetic longitudes started to pick up ULF wave activity around dawn (first vertical line on the left of the local noon annotation). The wave activity persisted toward local noon (vertical line indicated by the local noon annotation) and gradually disappeared in the late afternoon or dusk (vertical line on the right of the local noon annotation). 
Table 1

Coordinates of 30 Ground Magnetometer Stations Used in This study

\begin{tabular}{llrrrrr}
\hline Network & Station code & Geo lat $\left(^{\circ}\right)$ & Geo lon $\left(^{\circ}\right)$ & Mag lat $\left(^{\circ}\right)$ & Mag lon $\left(^{\circ}\right)$ & $L$ value \\
\hline DTU & THL & 77.47 & 290.77 & 84.18 & 26.26 & 999.99 \\
DTU & SVS & 76.02 & 294.90 & 82.46 & 30.21 & 999.99 \\
DTU & KUV & 74.57 & 302.82 & 80.16 & 39.35 & 999.99 \\
DTU & UPN & 72.78 & 303.85 & 78.36 & 37.98 & 999.99 \\
DTU & UMQ & 70.68 & 307.87 & 75.79 & 40.61 & 999.99 \\
DTU & GDH & 69.25 & 306.47 & 74.61 & 37.64 & 14.20 \\
DTU & ATU & 67.93 & 306.43 & 73.31 & 36.66 & 12.12 \\
DTU & SKT & 65.42 & 307.10 & 70.70 & 36.08 & 9.15 \\
DTU & GHB & 64.17 & 308.27 & 69.25 & 36.80 & 7.97 \\
DTU & FHB & 62.00 & 310.32 & 66.67 & 38.16 & 6.38 \\
DTU & NAQ & 61.16 & 314.56 & 65.00 & 42.32 & 5.60 \\
DTU & DMH & 76.77 & 341.37 & 77.17 & 81.96 & 999.99 \\
IMAGE & NAL & 78.92 & 11.95 & 76.58 & 108.19 & 999.99 \\
IMAGE & BJN & 74.50 & 19.20 & 71.80 & 106.02 & 10.25 \\
IMAGE & SOR & 70.54 & 22.22 & 67.68 & 104.69 & 6.93 \\
IMAGE & MAS & 69.46 & 23.70 & 66.52 & 105.09 & 6.30 \\
IMAGE & IVA & 68.56 & 27.29 & 65.48 & 107.41 & 5.81 \\
IMAGE & SOD & 67.37 & 26.63 & 64.28 & 106.18 & 5.31 \\
IMAGE & PEL & 66.90 & 24.08 & 63.87 & 103.81 & 5.16 \\
IMAGE & HAN & 62.25 & 26.60 & 58.99 & 103.81 & 3.77 \\
MACCS & GJO & 68.63 & 264.15 & 76.86 & 329.71 & 999.99 \\
NRCAN & CBB & 69.12 & 254.97 & 76.49 & 314.14 & 999.99 \\
CARISMA & FSIM & 61.76 & 238.77 & 67.10 & 296.24 & 6.60 \\
AUTUMN & INUV & 68.41 & 226.23 & 71.23 & 277.99 & 9.66 \\
AAL-PIP & PG0 & -83.67 & 88.68 & -78.52 & 38.49 & 999.99 \\
AAL-PIP & PG1 & -84.50 & 77.20 & -77.12 & 37.59 & 999.99 \\
AAL-PIP & PG2 & -84.42 & 57.96 & -75.39 & 39.28 & 15.72 \\
AAL-PIP & PG3 & -84.81 & 37.63 & -73.66 & 36.82 & 12.64 \\
AAL-PIP & PG4 & -83.34 & 12.25 & -70.96 & 36.33 & 9.39 \\
AAL-PIP & PG5 & -81.96 & 5.71 & -69.57 & 37.20 & 8.20 \\
\hline Note Ge & S & & & & \\
\hline
\end{tabular}

Note. Geomagnetic coordinates are in Corrected GeoMagnetic (CGM) coordinates based on the DGRF/IGRF geomagnetic field models for Epoch 2016. Geomagnetic coordinates and $L$ value calculations were done using https://omniweb. gsfc.nasa.gov/vitmo/cgm.html website. $L$ value of 999.99 indicates that the station is on open field lines.

In addition to the Greenland stations, we checked the ULF wave signatures from lower $L$ shells in the IMAGE stations to see how far these waves can penetrate into the inner magnetosphere. Figure 3 shows that the Pc5 wave power becomes significantly weaker beyond the IVA station $(L=5.81)$ and the wave power peaks at higher frequencies in the Pc3-4 frequency range at lower $L$ shells (e.g., the SOD, PEL, and HAN stations). We assume the inner boundary of Pc5 wave activity to be located somewhere between the IVA $(L=5.81)$ and $\operatorname{SOD}(L=5.31)$ stations, that is, $L \sim 5.5$. Note that the IMAGE stations are $4-5 \mathrm{hr}$ ahead of the DTU stations (Figure 1g), and they passed through noon when there are significant variations in the IMF and increase in cone angle (Figures 1a and 1b). This could lead to some differences in wave power variation with latitude compared to those observed from the DTU stations shown in Figure 2a. In addition to the ground magnetometers, the ground-based SuperDARN radars observed Pc5 ULF waves at other local times (Figure 4). As shown in Figure 4 (left column) from the Inuvik radar, the waves extended deep into the polar cap. Similar to the Pc5 pulsations observed at the DTU stations (Figure 2a), the ionospheric Pc5 waves at higher latitudes from the Inuvik radar are more irregular compared to those observed at lower latitudes from the Stokkseyri radar. To summarize, ground magnetometers and SuperDARN radars indicate that Pc5 wave activity extended from $L \sim 5.5$ deep into the polar cap.

In Figure 5, we show time series and integrated wave power distribution for the Pc5 frequency range (1-7 mHz) from two conjugate chains, that is, the DTU chain and the AAL-PIP chain. From the interhemispheric comparison of magnetic field time series, we can see that the $\mathrm{H}\left(B_{x}\right)$ component is mostly in phase between the hemispheres (Figure $5 \mathrm{a}$ ), while the $\mathrm{D}\left(B_{y}\right)$ component is out of phase at the conjugate points (Figure 5b), which is consistent with odd mode standing Alfvén waves (Sugiura \& Wilson, 1998). The 

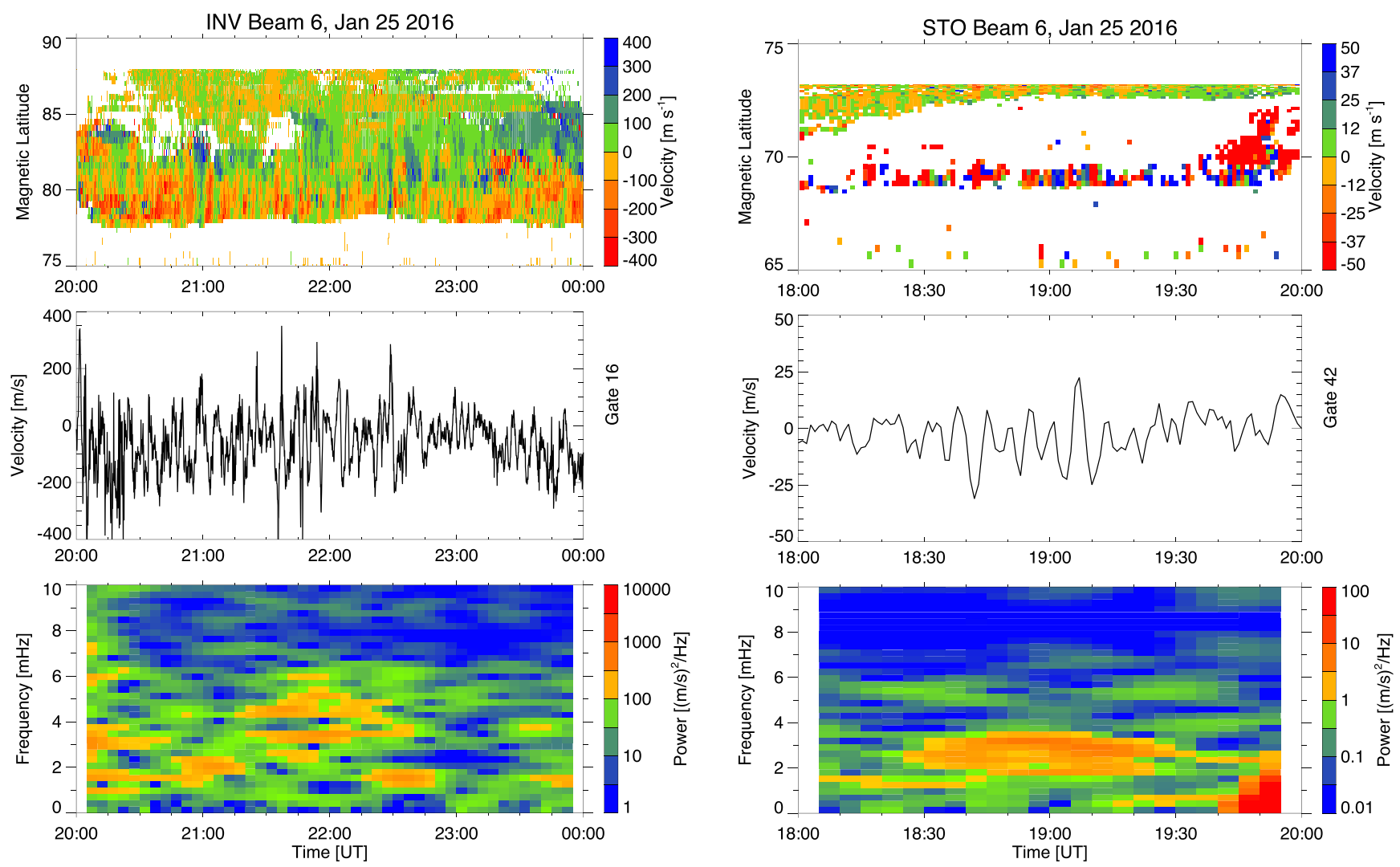

Figure 4. Left column: ionospheric ULF signatures observed by the Inuvik radar in the themis mode camping beam 6 ( $\sim 6 \mathrm{~s}$ resolution) from 25 January $2016 /$ 20:00 UT to 25 January 2016/24:00 UT. Right column: ionospheric ULF signatures observed by the Stokkseyri radar in ground scatter echoes from the normal beam 6 ( $\sim 60 \mathrm{~s}$ resolution) from 25 January 2016/18:00 UT to 25 January 2016/20:00 UT. From top to bottom are: the range-time intensity plot, Doppler velocity time series from specific range gate, and dynamic power spectrum of data from the above panel.

integrated wave power of the $\mathrm{H}$ component (Figure 5c) from higher (lower) latitudes tends to maximize (minimize) near noon. For the Pc5 toroidal component, the integrated wave power is generally stronger in the Northern Hemisphere (Figure 5c) than it is in the Southern Hemisphere (Figure 5e). The Pc5 wave power in the poloidal component (Figures $5 \mathrm{~d}$ and $5 \mathrm{f}$ ) dominates in the afternoon sector (after 14:00 UT) and is generally stronger in the Southern Hemisphere.

Numerous studies have shown that the fundamental eigenmode is the most powerful of the toroidal mode standing wave harmonics (e.g., Anderson et al., 1990; Takahashi et al., 1964). Takahashi et al. (2004) found that the fundamental toroidal mode frequency at $L>7$ often falls in the $2-4 \mathrm{mHz}$ range (Figure 11), consistent with the observations in this study. It is unlikely that the observations are higher harmonic waves, since that would require fundamental mode frequencies of 1-2 $\mathrm{mHz}$, lower than past reports of the fundamental mode frequency. The fundamental eigenfrequency also depends on geomagnetic activity and MLT. Therefore, we attribute these ULF waves with dominant power at $1-4 \mathrm{mHz}$ observed in this study to fundamental toroidal standing Alfvén waves. On the same day, long-lasting second harmonic poloidal Pc4 waves between 5 and $10 \mathrm{mHz}$ were observed in the dayside magnetosphere and ionosphere by two GOES satellites and three SuperDARN radars located at high latitudes (Shi et al., 2018). As these waves had high- $m$ numbers, they were screened by the ionosphere and thus not observed by the ground magnetometers.

\subsection{Observations From Space}

We now analyze wave signatures in the magnetosphere from MMS satellite observations. Although the local times of the MMS satellites were different from the DTU/AAL-PIP conjugate ground magnetometer observations (Figure 1g), the solar wind conditions were similar during this interval and the footprint of the MMS1 satellite passed near two other ground magnetometer stations (FSIM and INUV) as shown in 
(a)

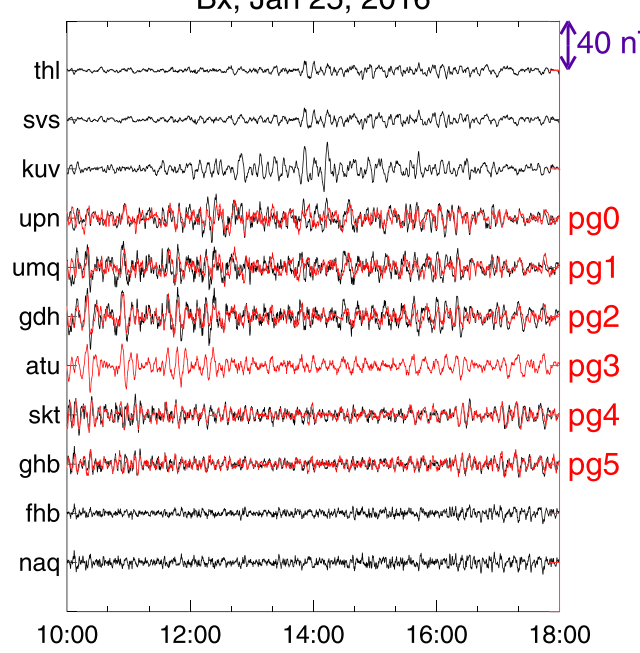

(c)

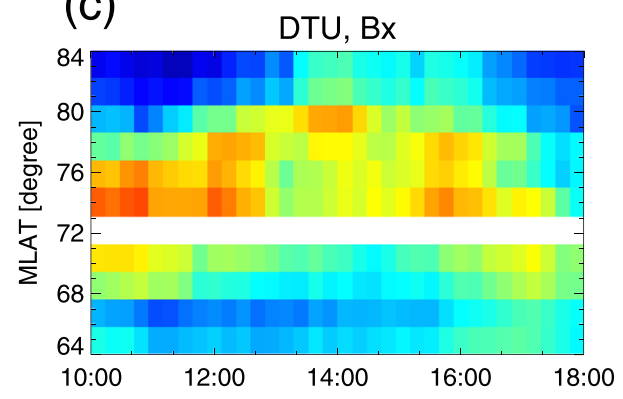

(e)

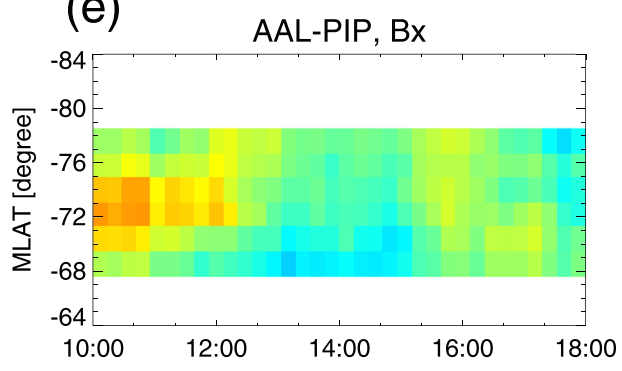

(b) By, Jan 25, 2016

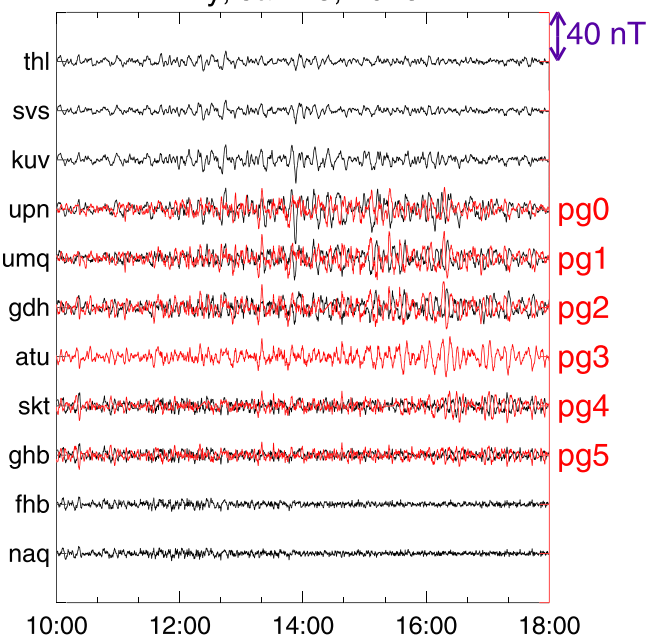

(d)

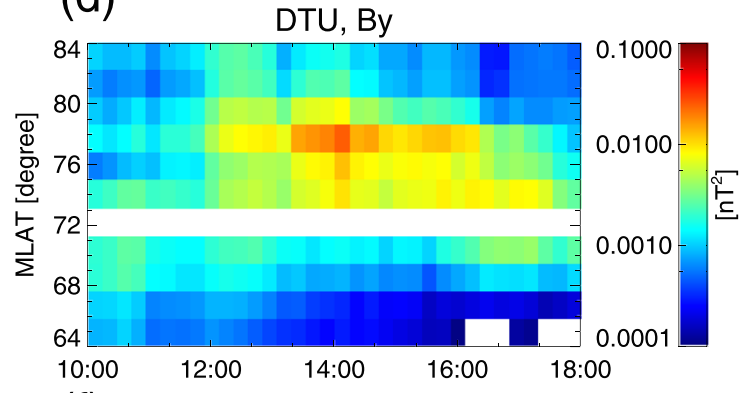

(f)

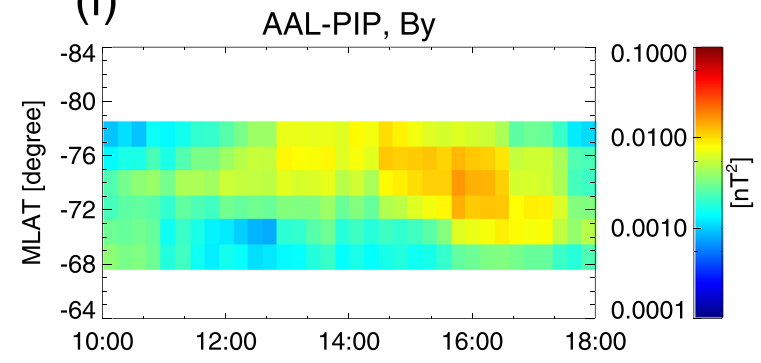

Figure 5. Interhemispheric comparison of ground magnetic field data from 10 to 18 UT on 25 January 2016 centered around local noon. Upper two panels show (a) time series of $B_{x}$ from the DTU (black) and AAL-PIP (red) stations and (b) time series of $B_{y}$ from the DTU (black) and AAL-PIP (red) stations. Lower four panels show variation of integrated wave power in the Pc5 frequency range with time and magnetic latitude for (c) DTU $B_{x}$, (d) DTU $B_{y}$, (e) AAL-PIP $B_{x}$, and (f) AAL-PIP $B_{y}$.

Figure 1g. Note that MMS1 crossed the magnetopause at about 03:30 UT (inbound) and moved very close to the magnetopause (outbound) at the end of this day. Figures $6 \mathrm{a}$ and $6 \mathrm{~b}$ show the IMF and dynamic pressure time series from the WIND satellite (45 min shifted) indicating upstream conditions. Monochromatic Pc5 waves were observed in the $B_{y}$ component (the azimuthal component in the mean field-aligned coordinates) measured by MMS1 at 17-19 UT (Figures 6c and 6d). Wave peak power frequency (black line in Figure 6d) and wave power gradually decreased as MMS1 moved outward to higher $L$ shells. The waveform also becomes more irregular, similar to the DTU chain observations (Figures 2a and 5a). The other three MMS satellites observed similar wave activity (not shown). FSIM and INUV stations at fixed $L$ shells observed Pc5 waves at similar frequencies throughout the 15-23 UT time interval. Wave power and peak power frequency gradually decreased after 21 UT as these stations moved toward local noon. 

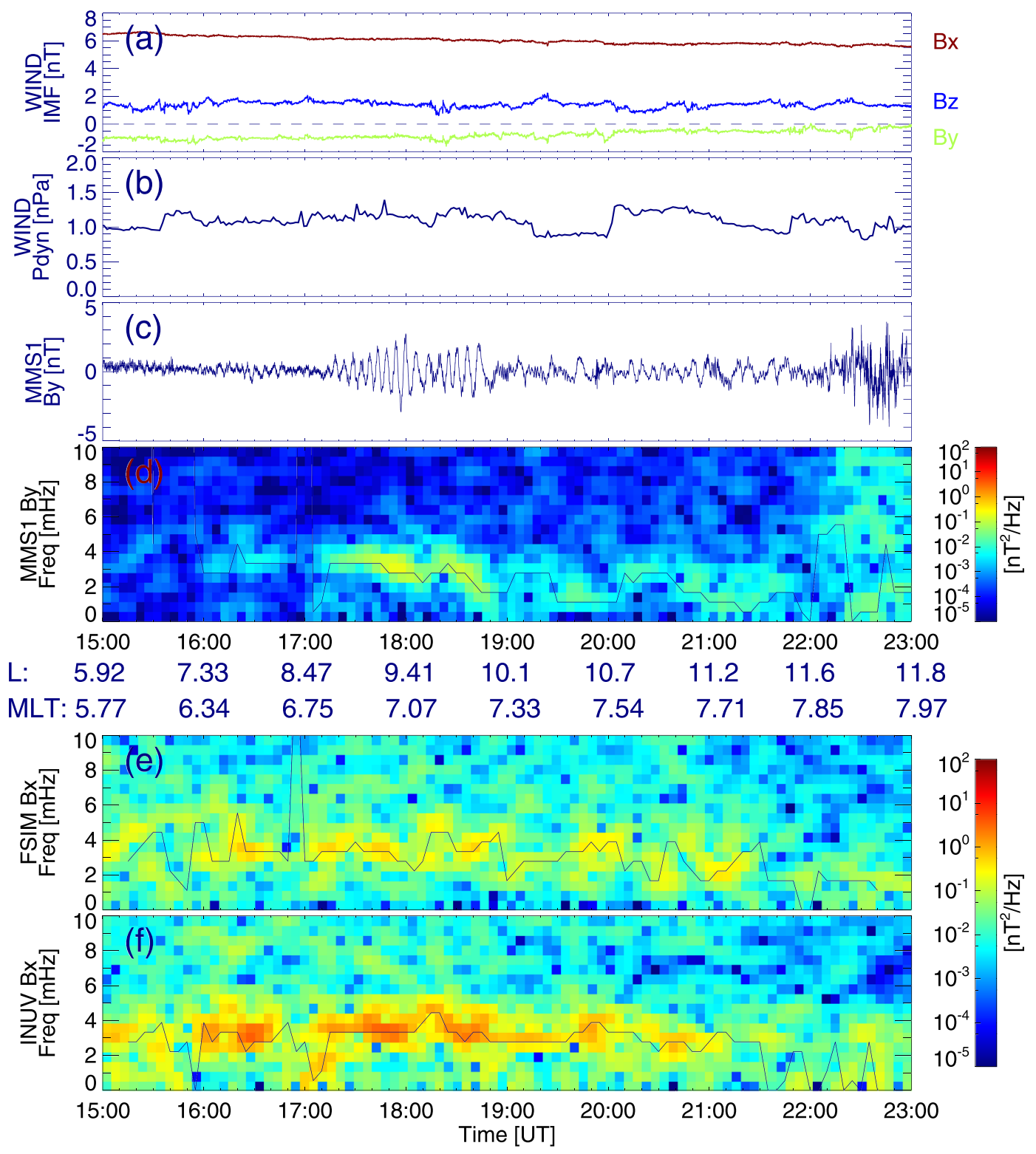

Figure 6. Coordinated observations of Pc5 waves from MMS1 and the FSIM an INUV ground magnetometers from 15:00 to 23:00 UT on 25 January 2016: (a) IMF components, (b) solar wind dynamic pressure, (c) MMS1 $B_{y}$ time series, (d) MMS1 $B_{y}$ dynamic power spectrum, (e) FSIM $B_{x}$ dynamic power spectrum, and (f) INUV $B_{x}$ dynamic power spectrum. Black solid traces in dynamic power spectra identify the peak power frequency variation with time.

To investigate the driver of the observed Pc5 waves, we examined plasma properties and magnetic field variations using MMS1 in situ measurements around the magnetopause when the satellite was located at MLT $\sim 8.7 \mathrm{hr}$. Figure 7 shows that there were surface wave signatures from 03:30 to 03:45 UT (i.e., magnetosheath and magnetospheric plasma conditions alternating on Pc5 timescales when MMS1 crossed the magnetopause). The surface wave signatures manifested themselves as quasiperiodic oscillations particularly in ion density (Figure 7b) and temperature (Figure 7c). These surface waves can propagate inward to the magnetosphere and couple with shear Alfvén waves when their frequencies match the local magnetic field eigenfrequency. They are likely to be the source for the ULF waves observed by the MMS1 satellite (Figure 6c) and ground magnetometers (Figures 2 and 3). Velocity shear across the magnetopause can drive surface waves which may develop into $\mathrm{KH}$ waves when the velocity shear is strong enough to trigger the $\mathrm{KH}$ instability. It is thus worthwhile checking if the magnetopause is $\mathrm{KH}$ unstable during this interval. 

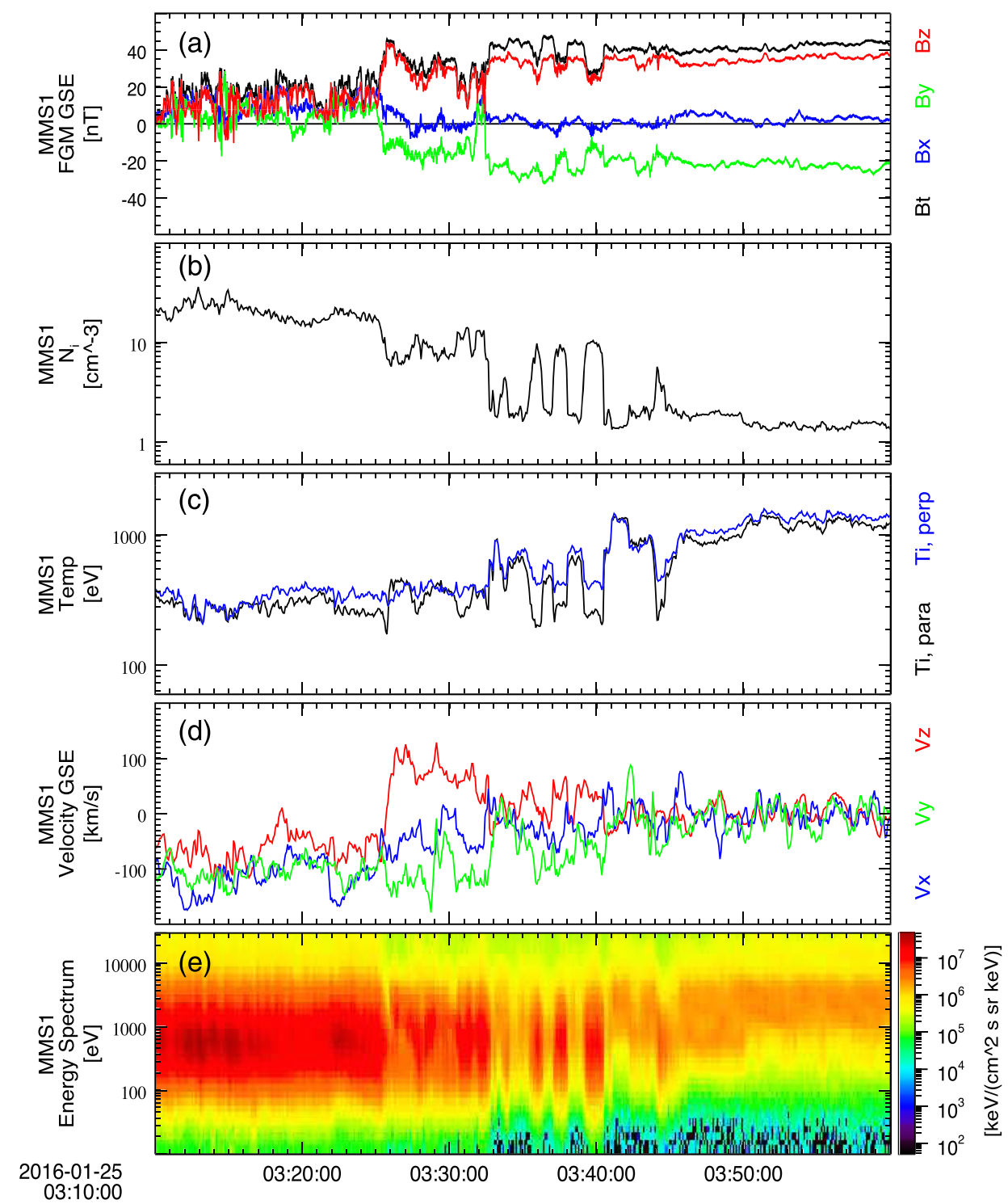

Figure 7. MMS1 observations of surface wave signatures at the magnetopause from 25 January 2016/03:10 UT to 25 January 2016/04:00 UT. From top to bottom are (a) magnetic field in GSE coordinates, (b) ion number density, (c) ion temperature, (d) plasma bulk velocity in GSE coordinates, and (e) ion omni energy spectrum.

The likelihood of KHI in this event is evaluated based on the instability criterion for incompressible plasmas separated by a tangential discontinuity (Chandrasekhar, 1961):

$$
\gamma=\sqrt{\frac{1}{m_{p}\left(n_{1}+n_{2}\right)}\left\{\frac{m_{p} n_{1} n_{2}}{n_{1}+n_{2}}(\Delta \vec{V} \cdot \vec{k})^{2}-\frac{1}{\mu_{0}},\left[\left(\vec{B}_{1} \cdot \vec{k}\right)^{2}+\left(\vec{B}_{2} \cdot \vec{k}\right)^{2}\right]\right\}}
$$

Table 2

Plasma Properties and Magnetic Field in the Unperturbed Magnetosheath and Magnetospheric Side

\begin{tabular}{lll}
\hline & \multicolumn{1}{c}{ Magnetosheath } & \multicolumn{1}{c}{ Magnetosphere } \\
\hline Density $\left(\mathrm{cm}^{-3}\right)$ & 30.38 & 1.40 \\
Magnetic field (nT), GSE & {$[7.65,7.39,6.14]$} & {$[2.22,-21.52,36.07]$} \\
Velocity $(\mathrm{km} / \mathrm{s}), \mathrm{GSE}$ & {$[-145,-124,-69]$} & {$[0,-1,3]$} \\
Temperature $(\mathrm{eV})$ & 462.6 & 2742.1 \\
\hline
\end{tabular}

where $\gamma$ is the growth rate, $m_{p}$ is the proton mass, $n_{i}$ and $\vec{B}_{i}$ are the background number density and magnetic field on each side of the magnetopause, and the subscript $i$ is 1 for the magnetosheath and 2 for the magnetosphere. $\Delta \vec{V}$ is the velocity shear across the magnetopause, while $\vec{k}$ is the wave vector. The most unstable direction of the wave vector can be determined by finding the maximum growth rate, which can be transformed into the following normalized form: 

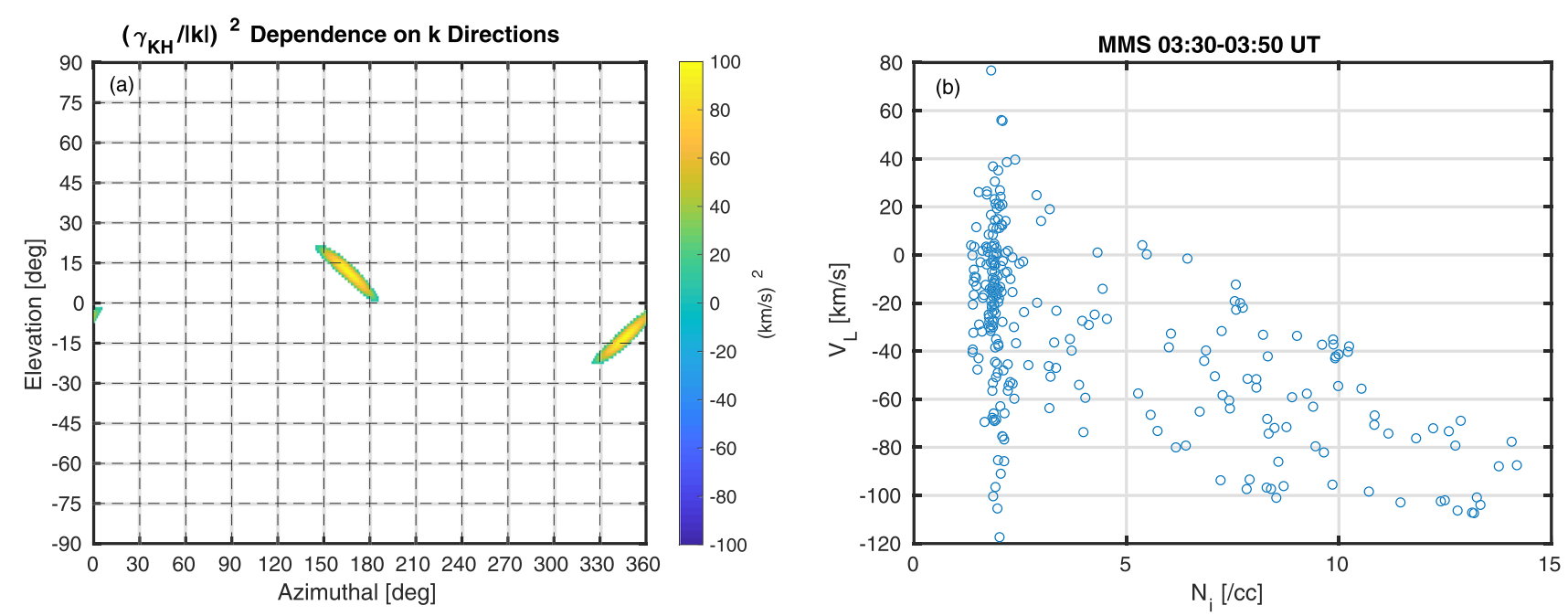

Figure 8. Examination of $\mathrm{KH}$ instability condition: (a) normalized growth rate dependence on the unit wave vector orientation and (b) scatter plot of $V_{L}$ versus $N_{i}$ from MMS1 observations at 03:30-03:50 UT on 25 January 2016.

$$
(\gamma / k)^{2}=a_{1} a_{2}(\Delta \vec{V} \cdot \hat{k})^{2}-a_{1}\left(\vec{V}_{A 1} \cdot \hat{k}\right)^{2}-a_{2}\left(\vec{V}_{A 2} \cdot \hat{k}\right)
$$

where $k$ is the wave number, $\hat{k}$ is the unit wave vector, $a_{i}=n_{i} /\left(n_{1}+n_{2}\right)$, and $\vec{V}_{A i}=\vec{B}_{i} /{\sqrt{\mu_{0} m_{p} n_{i}}}_{\text {is }}$ the Alfvén velocity in the background magnetosheath and magnetosphere for $i=1$ and 2, respectively.

The background density, magnetic field, velocity, and temperature in the magnetosheath and magnetosphere are estimated based on the ion specific entropy method introduced in Nykyri et al. (2020). The ion specific entropy is defined as $S=T n^{-2 / 3}$, where $T$ and $n$ are ion temperature and density, respectively. The interval between 03:10 and 04:00 UT was evaluated during which the ion specific entropy varies from about $S_{\min }=42.0 \mathrm{eV} \mathrm{cm}{ }^{2}$ in the magnetosheath side to about $S_{\max }=2,440.2 \mathrm{eV} \mathrm{cm}^{2}$ in the magnetospheric side. Magnetosheath plasma is thus identified where $S<S_{\min } \alpha$ and magnetospheric plasma is identified where $S>S_{\max } / \alpha$. Here we choose $\alpha=e^{5 \% * \log \left(S_{\max } / S_{\min }\right)}=1.23$. The average magnetosheath and magnetospheric plasma and magnetic field parameters computed using MMS1 FPI and FGM data between 03:10 and 04:00 UT are shown in Table 2.

The normalized $\mathrm{KH}$ growth rate $\gamma_{K H} / k$ dependence on the orientation of the unit wave vector is shown in Figure 8a. The azimuthal angle $\tan ^{-1}(y / x)$ and elevation angle $\sin ^{-1}(z / r), r=\sqrt{x^{2}+y^{2}+z^{2}}$ are defined in GSE coordinates where $180^{\circ}$ azimuthal angle is pointing tailward and $0^{\circ}$ elevation angle is in the $x y$ plane. The most unstable condition for this interval is found when the unit wave vector $\hat{k}$ is along $164^{\circ}$ azimuthal angle and $13^{\circ}$ elevation angle, that is, $\hat{k}=[-0.9403,0.2615,0.2176]$ in GSE coordinates. The maximum growth velocity corresponding to this direction is $\gamma_{K H} / k=9.9 \mathrm{~km} / \mathrm{s}$. In summary, this analysis shows that this interval is unstable to the $\mathrm{KHI}$ in the direction close to the equatorial plane and pointing tailward.

We further explored the KHI signatures by examining the so-called high-speed low-density (HSLD) structure, which implies a mixture of the fast and dense magnetosheath plasma and the slow and tenuous magnetospheric plasma due to the nonlinearly rolled-up KH vortices (Hasegawa et al., 2006; Lin et al., 2014). The local LMN coordinate system is determined with the minimum variance (MVA) method (Sonnerup \& Scheible, 2002) where $\mathrm{N}$ is the magnetopause normal direction determined by the MVA direction of the magnetic field, $\mathrm{M}$ is the cross product of $\mathrm{N}$ and the maximum variance direction of the ion velocity, and $\mathrm{L}$ completes the right-handed orthogonal coordinate system, which is approximately opposite to the magnetosheath flow direction. For this magnetopause crossing the three vectors are $L=[0.691,0.583,0$ $.427], M=[0.017,-0.604,0.797]$, and $N=[0.723,-0.544,-0.427]$. Figure $8 \mathrm{~b}$ shows the scatter plot of the ion density and plasma flow velocity along the $L$ direction. The bottom left corner of the scatter plot implies that there is mixture of magnetospheric and magnetosheath plasmas which may be attributed to the velocity shear-driven $\mathrm{KH}$ waves. 


\section{Discussion}

ULF waves extending from $L \sim 5.5$ into the polar cap region and across the whole dayside were observed by multiple ground magnetometers in both hemispheres on 25 January 2016. Perturbations in the toroidal component generally have larger power in the Northern Hemisphere than those in the Southern Hemisphere (Figures $5 \mathrm{c}$ and $5 \mathrm{e}$ ). The toroidal component has stronger wave power in the morning sector compared to the afternoon sector (Figures 2a, 2c, 5c, and 5e). For perturbations in the poloidal component, larger amplitudes were observed in the Southern Hemisphere afternoon sector (Figures $5 \mathrm{~d}$ and $5 \mathrm{f}$ ). It is unlikely that ionospheric conductivity could explain the north-south asymmetries seen at all magnetometer station pairs since the asymmetries in precipitation and solar radiation are different at different latitudes, yet we see similar patterns at all station pairs.

These interhemispheric and dawn-dusk asymmetries can be interpreted in terms of the IMF conditions and possible driving sources. As shown in Figure 1a, the IMF was dominated by an extended period of positive $B_{x}$, with slightly positive $B_{z}$, and negative $B_{y}$. Stronger toroidal mode wave power in the Northern Hemisphere can be explained by this IMF orientation. Namely, the radially IMF dominant configuration favors formation of an ion foreshock upstream of the magnetopause (Eastwood et al., 2005). When both $B_{x}$ and $B_{z}$ are positive, a quasi-parallel foreshock favors the Northern Hemisphere, leading to a more turbulent magnetosheath and elevated ULF disturbances in the Northern Hemisphere (Guglielmi et al., 2017; Hwang \& Sibeck, 2016).

The dawn-dusk asymmetry of toroidal mode standing Alfvén waves has long been attributed to the dawn-dusk asymmetry of the $\mathrm{KH}$ instability, which is expected from the asymmetry of the magnetosheath magnetic field that results from the IMF following the Parker spiral (Lee \& Olson, 1980). At the same time, larger seed perturbations for the KH instability would be expected at dawn during spiral IMF conditions that favor the formation of the ion foreshock prenoon, further enhancing surface wave amplitudes at dawn. However, Takahashi et al. (2015) have shown that fundamental toroidal mode standing Alfvén waves are stronger on the dawnside than on the duskside regardless of the orientation of the IMF due to the dawn-dusk asymmetry of the radial profile of the mass density, and the 3-D simulation work by Wright et al. (2018) also showed that FLRs are excited with larger amplitude at dawn compared to dusk in an asymmetric magnetospheric waveguide system that is driven symmetrically about the noon meridian. It is possible that both external (IMF orientation) and internal (radial mass density variation) mechanisms described above were active in the dayside magnetosphere on 25 January 2016.

It is very unlikely that such large spatial scale and steady long-lasting ULF waves observed on the dayside were excited by instabilities internal to the magnetosphere (e.g., Shi et al., 2018), which usually excite poloidal mode waves with large azimuthal wavenumber that are difficult to detect with ground magnetometers (Hughes \& Southwood, 1976). Thus, we discuss the possibility of an external upstream source. We first exclude the solar wind direct driving source and solar wind pressure pulse driving source, since neither quasiperiodic solar wind number density/pressure nor magnetic field variations at similar frequencies were observed by the upstream WIND satellite (Figures $6 \mathrm{a}$ and $6 \mathrm{~b}$ ). The dynamic pressure stayed around $1 \mathrm{nPa}$ for $8 \mathrm{hr}$ with some increases occurring at about 15:30, 20:00, and 21:50 UT. These dynamic pressure pulses might contribute to some of the wave intensification, but they were unlikely to be the dominant driver of the existing long-lasting Pc5 waves since these waves are present at all times and not only immediately following 15:30, 20:00, and 21:50 UT. One possible scenario is that the Pc5 waves observed on the dayside closed field lines are standing Alfvén waves coupled to compressional ULF waves driven by surface waves at the KH unstable magnetopause. This is supported by MMS observations of surface waves (Figure 7) at the $\mathrm{KH}$ unstable magnetopause (Figure 8) and SuperDARN radar observations in the ionosphere. Pc5 wave signatures from two SuperDARN radars (Figure 4) show an antisunward propagation in the morning and afternoon sectors. The azimuthal wave numbers estimated using the method from James et al. (2013) are $m \sim 2$ (eastward at $m l t \sim 17 \mathrm{hr}$ and mlat $\sim 72.5^{\circ}$ ) for the Stokkseyri radar (Figure 4 , right column) and $m \sim-2$ (westward at $m l t \sim 9 \mathrm{hr}$ and mlat $\sim 79.4^{\circ}$ ) for the Inuvik radar (Figure 4, left column). This is consistent with a surface wave/KHI driver. We also attempted to calculate azimuthal wave numbers from the MMS satellite data but found that their separations were insufficient to produce measurable differences in phase. Despite the radial dominant IMF on 25 January 2016, the steady northward IMF component (Figure 1a), which is a preferred condition for the growth of the $\mathrm{KH}$ instability, possibly provides a 
persistent mechanism for KH wave generation (Kavosi \& Raeder, 2015; Lin et al., 2014). Global magnetohydrodynamic (MHD) simulation results from Tang et al. (1984) have shown that KH instability can be excited at both flanks of the magnetosphere during radial IMF. THEMIS satellite observations from Grygorov et al. (2016) have also shown that $\mathrm{KH}$ waves were excited near the subsolar point $\left(Y_{G S M} \sim 4.5 R_{E}\right)$ by a large velocity shear at the low-latitude boundary layer inner edge under radial IMF.

Since radial IMF orientation dominated throughout this event, an ion foreshock formed upstream of the quasi-parallel bow shock introducing a broad range of perturbations such as the foreshock cavity and hot flow anomaly (Sibeck et al., 1990; Zhang et al., 1985). The more turbulent foreshock plays an important role in providing seed perturbations for the growth of KH waves (Hwang \& Sibeck, 2016; Miura, 1992; Nosé et al., 1995). We also know that foreshock transients can drive magnetopause perturbations and ripples with corresponding ULF perturbations in the absence of a KH unstable magnetopause (Sibeck, 2018). However, the foreshock transients alone cannot explain the observations. The local time distribution with peak near noon at high latitudes is consistent with large foreshock disturbances seeding the growth of surface waves via KHI, but it would not be consistent with the classic KHI picture where small upstream seed perturbations drive the surface waves-in this case, there is almost no wave power at noon (e.g., Claudepierre et al., 2009, 2016). Contrary to the wave power maximum near noon at high latitudes, the wave power maximized in the morning/afternoon sector at lower latitudes (Figures 5c). The lower-latitude peaks at dawn/dusk are consistent with surface waves coupling to standing Alfvén waves, while the high-latitude peaks are consistent with more direct observations of the seed perturbations for the surface waves (e.g., Guglielmi et al., 2017).

An outstanding issue is how Pc5 waves are generated in the cusp and polar cap region on open field lines. The polar cap has generally been thought to be a quiet region, with wave power entering only from neighboring regions, such as the auroral oval (e.g., Bland \& McDonald, 2016). As summarized in Engebretson et al. (2006) Pc5 waves from very high latitudes can be categorized into three classes according to their potential sources: cusp-related waves (Posch et al., 2016), polar pulsations extended from the auroral region, and $P i_{\text {cap }} 3$ independent of cusp and auroral pulsations (Yagova et al., 2018). For this particular event, it is possible that the Pc5 waves on open field lines also include Irregular Pulsations at Cusp Latitudes (IPCL) (Pilipenko et al., 2014), which come directly from the magnetosheath and foreshock region, generating waves with very similar properties across a wide range of $L$, from deep in the polar cap to $L \sim 5.5$. Global ULF wave models taking into account kinetic processes in the foreshock region and magnetosheath are needed to reveal the exact driving mechanism of this new type of Pc5 event extending from $L \sim 5.5$ into the polar cap.

Finally, it should be emphasized that the waves observed in this study can potentially cause geospace impacts. This study shows that during radial IMF, foreshock transients/KHI can lead to the generation of spatially extended Pc5 wave activity. These large-scale long-lasting Pc5 waves that propagate to the ground are potential drivers of geoelectric field/GIC that could cause pipeline corrosion. Additionally, the spatial variation of frequency and amplitude of geomagnetic perturbations as shown in this study using multipoint conjugate observations are important for predicting GIC (Pulkkinen et al., 1999) and radiation belt dynamics (Elkington, 2006). More work is needed to understand whether these types of waves have sufficient amplitude to generate significant $\mathrm{dB} / \mathrm{dt}$ and GIC.

\section{Conclusions}

Using conjugate interhemispheric observations, we have examined the properties of ULF waves observed across the entire dayside during an extended period of radial IMF. The waves were observed from $L \sim 5.5$ to the cusp and polar cap region with minimal frequency variations (1-4 mHz) over local time and latitude. Observations from MMS satellites and multiple interhemispheric ground magnetometers indicate that the Pc5 pulsations on closed field lines are fundamental toroidal mode standing Alfvén waves. Wave power from lower latitudes (more monochromatic waves) tends to maximize away from noon in the morning/afternoon sector, while wave power from higher latitudes (more irregular waves) tends to maximize near noon. The wave power distribution, antisunward propagation, and MMS satellite observations during the magnetopause crossing indicate $\mathrm{KH}$ instability-driven surface waves coupled with standing Alfvén waves. The upstream ion foreshock may provide seed perturbations for the growth of the $\mathrm{KH}$ instability which 
generates the dayside Pc5 waves. No previous study has shown that global and steady Pc5 wave activity as reported in our study could be associated with $B_{x}$ predominant conditions (or ion foreshock processes). This event is a good example of how low cone angle (and potentially ion foreshock processes) can be associated with Pc5 waves rather than only with Pc3-4 waves. Further investigations of this type of global and steady wave activity are needed to determine how often these driving conditions occur, to better assess how upstream foreshock/magnetosheath disturbances couple to magnetospheric ULF waves, and to determine whether these long-lasting Pc5 waves could cause geospace impacts such as GICs or radiation belt interactions.

\section{Acknowledgments}

The authors are grateful to Mary Hudson, Kazue Takahashi, Hui Zhang, and Heli Hietala for helpful discussions and valuable comments. D. L. is thankful to Dr. Xuanye Ma for the constructive discussions on $\mathrm{KHI}$ analysis. Work at Virginia Tech has been supported by the National Aeronautics and Space Administration (NASA) Headquarters under the NASA Earth and Space Science Fellowship Program-Grant 80NSSC17K0456 P00001, the National Science Foundation (NSF) Grant AGS-1341918, and NASA 80NSSC19K0907. M. D. H., Z. X., and S. C. were supported by NSF PLR-1543364 and PLR-1744828. D. L. was supported by the Advanced Study Program Postdoctoral Fellowship of the National Center for Atmospheric Research (NCAR). NCAR is sponsored by the NSF. We acknowledge the use of DTU, AAL-PIP, IMAGE, and AUTUMN ground magnetometer data. We thank the institutes who maintain the IMAGE Magnetometer Array: Troms Geophysical Observatory of UiT the Arctic University of Norway (Norway), Finnish Meteorological Institute (Finland), Institute of Geophysics Polish Academy of Sciences (Poland), GFZ German Research Centre for Geosciences (Germany), Geological Survey of Sweden (Sweden), Swedish Institute of Space Physics (Sweden), Sodankylä Geophysical Observatory of the University of Oulu (Finland), and Polar Geophysical Institute (Russia). We also wish to acknowledge the use of data from the MMS and WIND spacecraft. We would like to thank Johns Hopkins University Applied Physics Laboratory for providing the DMSP/SSUSI auroral FUV data (available at https://ssusi.jhuapl.edu/ data_products). The authors acknowledge the use of SuperDARN data. SuperDARN is a collection of radars funded by the national scientific funding agencies of Australia, Canada, China, France, Italy, Japan, Norway, South Africa, United Kingdom, and the United States. We thank the Virginia Tech SuperDARN group for the distribution of SuperDARN data via the website (http://vt.superdarn.org/tikiindex.php?page $=$ Data + Access)

\section{Data Availability Statement}

DTU data are obtained from the public Tromso Geophysical Observatory website (http://flux.phys.uit.no/ geomag.html). The Antarctic AAL-PIP data have been provided by Virginia Tech which is supported by NSF through the following awards for this purpose: ANT0839858, ATM922979, ANT0838861, PLR1243398, and PLR-1543364. The IMAGE magnetometer data are available online (https://space.fmi.fi/ image/www/index.php?page=user_defined\#). AUTUMN ground-based magnetometer data are available at http://autumn.athabascau.ca/website website. MMS data are available via MMS science data center (https://lasp.colorado.edu/mms/sdc/public/). Solar wind data from the Wind spacecraft were obtained through the CDAWeb (https://cdaweb.gsfc.nasa.gov/index.html/).

\section{References}

Anderson, B. J., Engebretson, M. J., Rounds, S. P., Zanetti, L. J., \& Potemra, T. A. (1990). A statistical study of Pc 3-5 pulsations observed by the AMPTE/CCE Magnetic Fields Experiment, 1. Occurrence distributions. Journal of Geophysical Research, 95(A7), 10,495-10,523. https://doi.org/10.1029/JA095iA07p10495

Baddeley, L. J., Yeoman, T. K., Wright, D. M., Trattner, K. J., \& Kellet, B. J. (2005). On the coupling between unstable magnetospheric particle populations and resonant high m ULF wave signatures in the ionosphere. Annales Geophysicae, 23(2), 567-577. https://doi.org/ 10.5194/angeo-23-567-2005

Bier, E. A., Owusu, N., Engebretson, M. J., Posch, J. L., Lessard, M. R., \& Pilipenko, V. A. (2014). Investigating the IMF cone angle control of Pc3-4 pulsations observed on the ground. Journal of Geophysical Research: Space Physics, 119, 1797-1813. https://doi.org/10.1002/ 2013JA019637

Bland, E. C., \& McDonald, A. J. (2016). High spatial resolution radar observations of ultralow frequency waves in the southern polar cap. Journal of Geophysical Research: Space Physics, 121, 4005-4016. https://doi.org/10.1002/2015JA022235

Chandrasekhar, S. (1961). Hydrodynamic and hydromagnetic stability, 652 pp., clarendon.

Claudepierre, S. G., Toffoletto, F. R., \& Wiltberger, M. (2016). Global MHD modeling of resonant ULF waves: Simulations with and without a plasmasphere. Journal of Geophysical Research: Space Physics, 121, 227-244. https://doi.org/10.1002/2015JA022048

Claudepierre, S. G., Wiltberger, M., Elkington, S. R., Lotko, W., \& Hudson, M. K. (2009). Magnetospheric cavity modes driven by solar wind dynamic pressure fluctuations. Geophysical Research Letters, 36, L13101. https://doi.org/10.1029/2009GL039045

Clauer, C. R., Kim, H., Deshpande, K., Xu, Z., Weimer, D., Musko, S., et al. (2014). An autonomous adaptive low-power instrument platform (AAL-PIP) for remote high-latitude geospace data collection. Geoscientific Instrumentation, Methods and Data Systems, 3(2), 211.

Crowley, G., Wade, N., Waldock, J. A., Robinson, T. R., \& Jones, T. B. (1985). High time-resolution observations of periodic frictional heating associated with a Pc5 micropulsation. Nature, 316(6028), 528.

Dessler, A. J. (1959). Upper atmosphere density variations due to hydromagnetic heating. Nature, 184(4682), 261.

Eastwood, J. P., Lucek, E. A., Mazelle, C., Meziane, K., Narita, Y., Pickett, J., \& Treumann, R. A.(2005). The foreshock. Space Science Reviews, 118(1-4), 41-94.

Elkington, S. R. (2006). A review of ULF interactions with radiation belt electrons. Geophysical Monograph-American Geophysical Union, $169,177$.

Elkington, S. R., Hudson, M. K., \& Chan, A. A. (1999). Acceleration of relativistic electrons via drift-resonant interaction with toroidal-mode Pc-5 ULF oscillations. Geophysical Research Letters, 26(21), 3273-3276. https://doi.org/10.1029/1999GL003659

Engebretson, M. J., Posch, J. L., Pilipenko, V. A., \& Chugunova, O. M. (2006). ULF waves at very high latitudes. Geophysical Monograph, 169, 137-156.

Grygorov, K., Němeěek, Z., Šafránková, J., Přech, L., Pi, G., \& Shue, J.-H. (2016). Kelvin-Helmholtz wave at the subsolar magnetopause boundary layer under radial IMF. Journal of Geophysical Research: Space Physics, 121, 9863-9879. https://doi.org/10.1002/2016JA023068

Guglielmi, A., Klain, B., \& Potapov, A. (2017). North-south asymmetry of ultra-low-frequency oscillations of Earth's electromagnetic field. Solar-Terrestrial Physics, 3(4), 26-31. https://doi.org/10.12737/stp-34201703

Hartinger, M., Angelopoulos, V., Moldwin, M. B., Glassmeier, K.-H., \& Nishimura, Y. (2011). Global energy transfer during a magnetospheric field line resonance. Geophysical Research Letters, 38, L12101. https://doi.org/10.1029/2011GL047846

Hartinger, M. D., Turner, D. L., Plaschke, F., Angelopoulos, V., \& Singer, H. (2013). The role of transient ion foreshock phenomena in driving Pc5 ULF wave activity. Journal of Geophysical Research: Space Physics, 118, 299-312. https://doi.org/10.1029/2012JA018349

Hasegawa, H., Fujimoto, M., Takagi, K., Saito, Y., Mukai, T., \& Réme, H. (2006). Single-spacecraft detection of rolled-up Kelvin-Helmholtz vortices at the flank magnetopause. Journal of Geophysical Research, 111, A09203. https://doi.org/10.1029/2006JA011728

Hughes, W. J., \& Southwood, D. J. (1976). The screening of micropulsation signals by the atmosphere and ionosphere. Journal of Geophysical Research, 81(19), 3234-3240. https://doi.org/10.1029/JA081i019p03234

Hwang, K.-J., \& Sibeck, D. G. (2016). Role of low-frequency boundary waves in the dynamics of the dayside magnetopause and the inner magnetosphere, Low frequency waves in space plasmas pp. 213-239): American Geophysical Union (AGU). https://doi.org/10.1002/ 9781119055006.ch13 
Jacobs, J. A., Kato, Y., Matsushita, S., \& Troitskaya, V. A. (1964). Classification of geomagnetic micropulsations. Journal of Geophysical Research, 69(1), 180-181. https://doi.org/10.1029/JZ069i001p00180

James, M. K., Yeoman, T. K., Mager, P. N., \& Klimushkin, D. Y. (2013). The spatio-temporal characteristics of ULF waves driven by substorm injected particles. Journal of Geophysical Research: Space Physics, 118, 1737-1749. https://doi.org/10.1002/jgra.50131

Karatay, S., Arikan, F., \& Arikan, O. (2010). Investigation of total electron content variability due to seismic and geomagnetic disturbances in the ionosphere. Radio Science, 45, RS5012. https://doi.org/10.1029/2009RS004313

Kavosi, S., \& Raeder, J. (2015). Ubiquity of Kelvin-Helmholtz waves at Earth's magnetopause. Nature Communications, 6, 7019.

Kepko, L., \& Spence, H. E. (2003). Observations of discrete, global magnetospheric oscillations directly driven by solar wind density variations. Journal of Geophysical Research, 108(A6), 1257. https://doi.org/10.1029/2002JA009676

Kilcommons, L. M., Redmon, R. J., \& Knipp, D. J. (2017). A new DMSP magnetometer and auroral boundary data set and estimates of field-aligned currents in dynamic auroral boundary coordinates. Journal of Geophysical Research: Space Physics, 122, 9068-9079. https:// doi.org/10.1002/2016JA023342

Lee, L. C., \& Olson, J. V. (1980). Kelvin-Helmholtz instability and the variation of geomagnetic pulsation activity. Geophysical Research Letters, 7(10), 777-780. https://doi.org/10.1029/GL007i010p00777

Lin, D., Wang, C., Li, W., Tang, B., Guo, X., \& Peng, Z. (2014). Properties of Kelvin-Helmholtz waves at the magnetopause under northward interplanetary magnetic field: Statistical study. Journal of Geophysical Research: Space Physics, 119, 7485-7494. https://doi.org/10.1002/ 2014JA020379

Mathie, R. A., \& Mann, I. R. (2000). A correlation between extended intervals of ULF wave power and storm-time geosynchronous relativistic electron flux enhancements. Geophysical Research Letters, 27(20), 3261-3264. https://doi.org/10.1029/2000GL003822

Menk, F. W., Orr, D., Clilverd, M. A., Smith, A. J., Waters, C. L., Milling, D. K., \& Fraser, B. J.(1999). Monitoring spatial and temporal variations in the dayside plasmasphere using geomagnetic field line resonances. Journal of Geophysical Research, 104(A9), $19,955-19,969$.

Miura, A. (1992). Kelvin-Helmholtz instability at the magnetospheric boundary: Dependence on the magnetosheath sonic Mach number. Journal of Geophysical Research, 97(A7), 10,655-10,675. https://doi.org/10.1029/92JA00791

Nosé, M., Iyemori, T., Sugiura, M., \& Slavin, J. A. (1995). A strong dawn/dusk asymmetry in Pc5 pulsation occurrence observed by the DE-1 satellite. Geophysical Research Letters, 22(15), 2053-2056. https://doi.org/10.1029/95GL01794

Nykyri, K., Ma, X., Burkholder, B., Rice, R., Johnson, J. R., Kim, E.-H., et al. (2020). MMS observations of the Multi-Scale wave structures and parallel electron heating in the vicinity of the southern exterior cusp. Earth and Space Science Open Archive, 41. https://doi.org/ 10.1002/essoar.10503470.1

Omidi, N., Sibeck, D., Gutynska, O., \& Trattner, K. J. (2014). Magnetosheath filamentary structures formed by ion acceleration at the quasi-parallel bow shock. Journal of Geophysical Research: Space Physics, 119, 2593-2604. https://doi.org/10.1002/2013JA019587

Palmroth, M., Archer, M., Vainio, R., Hietala, H., Pfau-Kempf, Y., Hoilijoki, S., et al. (2015). ULF foreshock under radial IMF: THEMIS observations and global kinetic simulation Vlasiator results compared. Journal of Geophysical Research: Space Physics, 120, 8782-8798. https://doi.org/10.1002/2015JA021526

Palmroth, M., Hietala, H., Plaschke, F., Archer, M., Karlsson, T., Blanco-Cano, X., et al. (2018). Magnetosheath jet properties and evolution as determined by a global hybrid-Vlasov simulation. Annales Geophysicae, 36(5), 1171-1182. https://doi.org/10.5194/angeo-36-1171-2018

Pilipenko, V., Belakhovsky, V., Kozlovsky, A., Fedorov, E., \& Kauristie, K. (2014). ULF wave modulation of the ionospheric parameters: Radar and magnetometer observations. Journal of Atmospheric and Solar-Terrestrial Physics, 108, 68-76.

Pilipenko, V., Belakhovsky, V., Murr, D., Fedorov, E., \& Engebretson, M. (2014). Modulation of total electron content by ULF Pc5 waves Journal of Geophysical Research: Space Physics, 119, 4358-4369. https://doi.org/10.1002/2013JA019594

Pilipenko, V. A., Kozyreva, O. V., Lorentzen, D. A., \& Baddeley, L. J. (2018). The correspondence between dayside long-period geomagnetic pulsations and the open-closed field line boundary. Journal of Atmospheric and Solar-Terrestrial Physics, 170, 64-74.

Pollock, C., Moore, T., Jacques, A., Burch, J., Gliese, U., Saito, Y., et al. (2016). Fast plasma investigation for magnetospheric multiscale. Space Science Reviews, 199(1-4), 331-406.

Posch, J. L., Engebretson, M. J., Weatherwax, A. T., Detrick, D. L., Hughes, W. J., \& Maclennan, C. G. (1999). Characteristics of broadband ULF magnetic pulsations at conjugate cusp latitude stations. Journal of Geophysical Research: Space Physics, 104(A1), 311-331. https:// doi.org/10.1029/98JA02722

Pulkkinen, A., Bernabeu, E., Thomson, A., Viljanen, A., Pirjola, R., Boteler, D., et al. (2017). Geomagnetically induced currents: Science, engineering, and applications readiness. Space Weather, 15, 828-856. https://doi.org/10.1002/2016SW001501

Pulkkinen, A., \& Kataoka, R. (2006). S-transform view of geomagnetically induced currents during geomagnetic superstorms. Geophysical Research Letters, 33, L12108. https://doi.org/10.1029/2006GL025822

Rae, I. J., Donovan, E. F., Mann, I. R., Fenrich, F. R., Watt, C. E. J., Milling, D. K., et al. (2005). Evolution and characteristics of global Pc5 ULF waves during a high solar wind speed interval. Journal of Geophysical Research, 110, A12211. https://doi.org/10.1029/ 2005JA011007

Rae, I. J., Watt, C. E. J., Fenrich, F. R., Mann, I. R., Ozeke, L. G., \& Kale, A. (2008). Energy deposition in the ionosphere through a global field line resonance. Annales Geophysicae, 25(12), 2529-2539.

Russell, C. T., Anderson, B. J., Baumjohann, W., Bromund, K. R., Dearborn, D., Fischer, D., et al. (2016). The magnetospheric multiscale magnetometers. Space Science Reviews, 199(1-4), 189-256.

Russell, C. T., Luhmann, J. G., Odera, T. J., \& Stuart, W. F. (1983). The rate of occurrence of dayside Pc 3,4 pulsations: The L-value dependence of the IMF cone angle effect. Geophysical Research Letters, 10(8), 663-666. https://doi.org/10.1029/GL010i008p00663

Shen, X.-C., Shi, Q., Wang, B., Zhang, H., Hudson, M. K., Nishimura, Y., et al. (2018). Dayside magnetospheric and ionospheric responses to a foreshock transient on 25 June 2008: 1. FLR Observed by satellite and ground-based magnetometers. Journal of Geophysical Research: Space Physics, 123, 6335-6346. https://doi.org/10.1029/2018JA025349

Shepherd, S. G. (2014). Altitude-adjusted corrected geomagnetic coordinates: Definition and functional approximations. Journal of Geophysical Research: Space Physics, 119, 7501-7521. https://doi.org/10.1002/2014JA020264

Shi, X., Baker, J. B. H., Ruohoniemi, J. M., Hartinger, M. D., Murphy, K. R., Rodriguez, J. V., et al. (2018). Long-lasting poloidal ULF waves observed by multiple satellites and high-latitude SuperDARN radars. Journal of Geophysical Research: Space Physics, 123, 8422-8438. https://doi.org/10.1029/2018JA026003

Sibeck, D. G. (1990). A model for the transient magnetospheric response to sudden solar wind dynamic pressure variations. Journal of Geophysical Research, 95(A4), 3755-3771. https://doi.org/10.1029/JA095iA04p03755

Sibeck, D. G., Phan, T.-D., Lin, R., Lepping, R. P., \& Szabo, A. (2002). Wind observations of foreshock cavities: A case study. Journal of Geophysical Research, 107(A10), SMP-4. 
Sonnerup, B. U. O., \& Scheible, M. (1998). Minimum and maximum variance analysis. Analysis methods for multi-spacecraft data. Sugiura, M., \& Wilson, C. R. (1964). Oscillation of the geomagnetic field lines and associated magnetic perturbations at conjugate points Journal of Geophysical Research, 69(7), 1211-1216. https://doi.org/10.1029/JZ069i007p01211

Takahashi, K., Denton, R. E., Anderson, R. R., \& Hughes, W. J. (2004). Frequencies of standing alfvén wave harmonics and their implication for plasma mass distribution along geomagnetic field lines: Statistical analysis of CRRES data. Journal of Geophysical Research, 109, A08202. https://doi.org/10.1029/2003JA010345

Takahashi, K., Hartinger, M. D., Angelopoulos, V., \& Glassmeier, K.-H. (2015). A statistical study of fundamental toroidal mode standing Alfvén waves using THEMIS ion bulk velocity data. Journal of Geophysical Research: Space Physics, 120, 6474-6495. https://doi.org/ 10.1002/2015JA021207

Takahashi, K., Lee, D.-H., Merkin, V. G., Lyon, J. G., \& Hartinger, M. D. (2016). On the origin of the dawn-dusk asymmetry of toroidal Pc5 waves. Journal of Geophysical Research: Space Physics, 121, 9632-9650. https://doi.org/10.1002/2016JA023009

Takahashi, K., McPherron, R. L., \& Terasawa, T. (1984). Dependence of the spectrum of Pc 3-4 pulsations on the interplanetary magnetic field. Journal of Geophysical Research, 89(A5), 2770-2780. https://doi.org/10.1029/JA089iA05p02770

Tang, B. B., Wang, C., \& Li, W. Y. (2013). The magnetosphere under the radial interplanetary magnetic field: A numerical study. Journal of Geophysical Research: Space Physics, 118, 7674-7682. https://doi.org/10.1002/2013JA019155

Tanskanen, E. I. (2009). A comprehensive high-throughput analysis of substorms observed by IMAGE magnetometer network: Years 1993-2003 examined. Journal of Geophysical Research: Space Physics, 114, A05204. https://doi.org/10.1029/2008JA013682

Wang, B., Nishimura, Y., Hietala, H., Shen, X.-C., Shi, Q., Zhang, H., et al. (2018). Dayside magnetospheric and ionospheric responses to a foreshock transient on 25 June 2008: 2. 2-D Evolution based on dayside auroral imaging. Journal of Geophysical Research: Space Physics, 123, 6347-6359. https://doi.org/10.1029/2017JA024846

Wright, A. N., Elsden, T., \& Takahashi, K. (2018). Modeling the dawn/dusk asymmetry of field line resonances. Journal of Geophysical Research: Space Physics, 123, 6443-6456. https://doi.org/10.1029/2018JA025638

Yagova, N. V., Pilipenko, V. A., Lanzerotti, L. J., Engebretson, M. J., Rodger, A. S., Lepidi, S., \& Papitashvili, V. O. (2004). Two-dimensional structure of long-period pulsations at polar latitudes in Antarctica. Journal of Geophysical Research, 109, A03222. https://doi.org/ 10.1029/2003JA010166

Yumoto, K., Saito, T., Akasofu, S.-I., Tsurutani, B. T., \& Smith, E. J. (1985). Propagation mechanism of daytime Pc 3-4 pulsations observed at synchronous orbit and multiple ground-based stations. Journal of Geophysical Research: Space Physics, 90(A7), 6439-6450. https://doi. org/10.1029/JA090iA07p06439

Zhang, H., Sibeck, D. G., Zong, Q.-G., Omidi, N., Turner, D., \& Clausen, L. B. N. (2013). Spontaneous hot flow anomalies at quasi-paralle shocks: 1. Observations. Journal of Geophysical Research: Space Physics, 118, 3357-3363. https://doi.org/10.1002/jgra.50376

Zhang, X. Y., Zong, Q.-G., Wang, Y. F., Zhang, H., Xie, L., Fu, S. Y., et al. (2010). ULF waves excited by negative/positive solar wind dynamic pressure impulses at geosynchronous orbit. Journal of Geophysical Research, 115, A10221. https://doi.org/10.1029/2009JA015016

Zong, Q., Rankin, R., \& Zhou, X. (2017). The interaction of ultra-low-frequency Pc3-5 waves with charged particles in Earth's magnetosphere. Reviews of Modern Plasma Physics, 1(1), 10. 